\title{
Ambulatory vital signs in the workup of pulmonary embolism using a standardized 3-minute walk test
}

\author{
Qamar Amin, MD*; Jeffrey J. Perry, MD, MSc*; Ian G. Stiell, MD, MSc*; Subhra Mohapatra, BSc*;
} Abdulaziz Alsadoon, $\mathrm{MD}^{*}$; Marc Rodger, $\mathrm{MD}, \mathrm{MSc}^{\dagger}$

\section{ABSTRACT}

Objective: Diagnosing pulmonary embolism can be difficult given its highly variable clinical presentation. Our objective was to determine whether a decrease in oxygen saturation or an increase in heart rate while ambulating could be used as an objective tool in the diagnosis of pulmonary embolism.

Methods: This was a two-site tertiary-care-centre prospective cohort study that enrolled adult emergency department or thrombosis clinic patients with suspected or newly confirmed pulmonary embolism. Patients were asked to participate in a standardized 3-minute walk test, which assessed ambulatory heart rate and ambulatory oxygen saturation. The primary outcome was pulmonary embolism.

Results: We enrolled 114 patients, including 30 with pulmonary embolism (26.3\%). A $\geq 2 \%$ absolute decrease in ambulatory oxygen saturation and an ambulatory change in heart rate $>10$ beats per minute (BPM) were significantly associated with pulmonary embolism. An ambulatory heart rate change of $>10$ BPM had a sensitivity of $96.6 \%$ (95\% confidence interval [Cl] 83.3 to 99.4$)$ and a specificity of $31.0 \%(95 \% \mathrm{Cl}$ 22.1 to 45.0 ) for pulmonary embolism. $A \geq 2 \%$ absolute decrease ambulatory oxygen saturation had a sensitivity of $80.2 \%(95 \% \mathrm{Cl} 62.7$ to 90.5$)$ and a specificity of $39.3 \%(95 \% \mathrm{Cl}$ 29.5 to 50.0$)$ for pulmonary embolism. The combination of both variables yielded a sensitivity of $100.0 \%(95 \% \mathrm{Cl} 87.0$ to $100.0)$ and a specificity of $11.0 \%$ (95\% Cl 6.6 to 21.0$)$.

Conclusion: In summary, our study found that an ambulatory heart rate change of $>10 \mathrm{BPM}$ or $\mathrm{a} \geq 2 \%$ absolute decrease in ambulatory oxygen saturation from baseline during a standardized 3-minute walk test are highly correlated with pulmonary embolism. Although the findings appear promising, neither of these variables can currently be recommended as a screening tool for pulmonary embolism until larger prospective studies examine their performance either alone or with pre-existing rules.

\section{RÉSUMÉ}

Objectif: L'embolie pulmonaire peut être difficile à diagnostiquer étant donné son tableau clinique très variable. L'étude visait à déterminer si une diminution du degré de saturation du sang en oxygène ou une augmentation de la fréquence cardiaque en cours de déambulation pouvait servir d'outil objectif de diagnostic de l'embolie pulmonaire.

Méthode: II s'agit d'une étude prospective de cohortes, menée dans deux centres hospitaliers de soins tertiaires, à laquelle ont participé des patients provenant d'un service d'urgence pour adultes et d'un centre de thrombose, chez qui était soupçonnée ou avait été confirmée depuis peu une embolie pulmonaire. L'on a demandé aux patients de participer à une épreuve de marche normalisée de 3 minutes au cours de laquelle étaient évalués la fréquence cardiaque et le degré de saturation du sang en oxygène, en mode ambulatoire. Le principal critère d'évaluation était l'embolie pulmonaire.

Résultats: Ont participé à l'étude 114 patients, dont 30 souffraient d'une embolie pulmonaire (26,3\%). Une diminution absolue $\geq 2 \%$ du degré de saturation du sang en oxygène en cours de marche et une modification de la fréquence cardiaque $>10$ battements par minute (BPM), aussi en cours de marche, étaient significativement associées à une embolie pulmonaire. Une modification de la fréquence cardiaque $>10$ BPM en mode ambulatoire avait une sensibilité de 96,6 \% (IC à $95 \%$ : 83,3$99,4$ ) et une spécificité de 31,0\% (IC à $95 \%: 22,1-45,0)$ à l'égard de l'embolie pulmonaire. Quant à la diminution absolue $\geq 2 \%$ du degré de saturation du sang en oxygène en mode ambulatoire, elle avait une sensibilité de $80,2 \%$ (IC à $95 \%$ : $62,7-90,5$ ) et une spécificité de 39,3\% (IC à $95 \%: 29,5-50,0$ ) à l'égard de l'embolie pulmonaire. L'association des deux variables avait une sensibilité de 100,0 \% (IC à $95 \%$ : 87,0100,0 ) et une spécificité de 11,0\% (IC à $95 \%: 6,6-21,0$ ).

Conclusions: Bref, il ressort de l'étude qu'une modification de la fréquence cardiaque $>10$ BPM en mode ambulatoire ou une diminution absolue $\geq 2 \%$ du degré de saturation du sang en oxygène en mode ambulatoire par rapport au départ, au cours d'une épreuve de marche normalisée de 3 minutes, sont en étroite corrélation avec l'embolie pulmonaire. Certes, ces résultats semblent prometteurs, mais il n'est pas possible à I'heure actuelle de recommander l'une ou l'autre de ces variables comme outil de dépistage de l'embolie pulmonaire jusqu'à ce que des études prospectives, plus importantes aient été menées sur leur performance, que ces

From the *Department of Emergency Medicine, Department of Medicine; and tDivision of Hematology Clinical Epidemiology Program, Ottawa Hospital Research Institute, University of Ottawa, ON.

Correspondence to: Dr. Jeffrey J. Perry, Clinical Epidemiology Unit, F6, Ottawa Hospital, 1053 Carling Avenue, Ottawa, ON K1Y 4E9; Email: jperry@ ohri.ca 
variables soient employées seules ou en association avec des règles préexistantes.
Keywords: Pulmonary Embolism, Walk-test, Ambulatory

Vital Signs

\section{INTRODUCTION}

\section{Background}

Chest pain and shortness of breath are two of the most common presenting patient complaints in the emergency department (ED). ${ }^{1}$ Pulmonary embolism is a potentially lethal yet treatable condition that must be considered in patients with these complaints. ${ }^{2-4}$ It has an annual incidence of 21 to $69 / 100,000$ population, is the third leading cause of cardiovascular mortality in North America, and causes 5\%-10\% of in-hospital deaths. ${ }^{2}$ The per-person lifetime incidence of pulmonary embolism is approximately $5 \% .^{2-5}$

The diagnosis of pulmonary embolism is important, given that undiagnosed pulmonary embolism is believed to have a mortality rate approaching $30 \%$. This falls to less than $8 \%$ if pulmonary embolism is diagnosed and appropriately treated. ${ }^{6-9}$ Diagnosing pulmonary embolism can be challenging because it is in the differential diagnosis of many common clinical presentations, including chest pain, shortness of breath, and hemoptysis. Studies suggest that only $8 \%-30 \%$ of patients suspected of having a pulmonary embolism actually have the condition. ${ }^{10-13}$ As a result, many patients without pulmonary embolism are needlessly anticoagulated, often due, in part, to delays in diagnostic imaging and obtaining a definitive diagnosis. Such patients may undergo extensive testing or hospitalization.

Currently, a myriad of clinical decision tools with variability in their interpretation exists for pulmonary embolism. ${ }^{12,14,15}$ Existing rules include various objective measures, but none include a quick, easy, objective bedside measurement. The performance of a standardized 3-minute walk test to obtain an ambulatory oxygen saturation and heart rate has been previously studied in other disease processes. ${ }^{16}$ The 3 -minute walk test has been found to be a simple, low-cost test, which is easy to conduct in a busy clinical setting for the diagnostic management of chronic obstructive pulmonary disease and heart failure. ${ }^{16,17}$ The objective of this study was to assess the utility of a change in ambulatory oxygen saturation and ambulatory heart rate measurement by means of a standardized 3-minute walk test, for the diagnosis of pulmonary embolism.

\section{MATERIALS AND METHODS}

\section{Study design}

We conducted a prospective cohort study of patients with a suspected (based on physician gestalt) or recently confirmed (based on imaging studies) pulmonary embolism. All participants underwent a standardized 3 -minute walk test. Strict stopping rules were used, and participants had the option to stop the test at any point for any reason beyond those listed in the stopping rules. The results of the walk test were not provided to clinicians unless a diagnostic and/or therapeutic decision was already made. The results of the 3-minute walk test were not incorporated into the ED care and management of participants. The research ethics board of the Ottawa Hospital approved the study. Verbally informed consent was obtained from all participants.

\section{Study setting}

The study was conducted in the EDs of two sites of the Ottawa Hospital—an adult, tertiary-care institution affiliated with the University of Ottawa. The involved EDs have an annual census of approximately 140,000 visits. Patients were also recruited at the Ottawa Hospital Thrombosis Clinic. This clinic is responsible for the diagnosis and management of all suspected or confirmed pulmonary embolisms in the greater Ottawa area. Several regional EDs, including those of the Ottawa Hospital, send all confirmed and many suspected patients with pulmonary embolism to this clinic for diagnosis (when unestablished) and further management of pulmonary embolism. The participants enrolled at the thrombosis clinic were patients assessed in an ED during the previous day. Most patients assessed in the clinic did not yet have definitive imaging to establish the diagnosis of pulmonary embolus.

\section{Selection of participants}

Adult patients over the age of 18 years who were physically able to participate in a walk test and who received, or were designated to receive, diagnostic imaging to assess for pulmonary embolism were eligible. We excluded 
patients who had a diagnosed pulmonary embolism in the past 3 months, were nonambulatory (e.g., paralysed, or in a wheelchair), required supplemental oxygenation during their ED visit, were receiving treatment for confirmed venous thromboembolism (anticoagulants or inferior vena cava filter), required therapeutic anticoagulation for other indications at the time of enrolment, or had any contraindications to the computed tomography pulmonary angiogram (e.g., renal impairment, contrast allergy).

The decision to initiate treatment was made by attending emergency physicians, based on positive imaging results completed in the ED and/or by risk stratification (by specific risk score or physician judgement), which in the case of high-risk patients typically involved commending treatment for pulmonary embolism and then referred to the thrombosis clinic. The decision to continue or discontinue treatment was made independently at the discretion of the attending physician or supervised resident at the Ottawa Hospital Thrombosis Clinic.

\section{Methods and measurements}

Trained research assistants were deployed in both the ED and thrombosis clinic to screen for potential participants. We opted to use this clinic as an enrolment site in order to increase our enrolment rate. A paid research assistant covered the thrombosis clinic from Monday to Friday. In the ED, study enrolment occurred 7 days a week from 8:00 am to 8:00 pm between May and November 2012. A small number of days were not covered due to lack of staffing. ED coverage was accomplished using a medical student volunteer and the principal investigator. Treating physicians were able to recommend patients for study enrolment. The 3-minute walk-test protocol was as follows: initial baseline vitals were taken (i.e., heart rate, oxygen saturation level, and respiration rate), and patients were asked to walk for a fixed period of 3 minutes regardless of the distance covered on ground level within the ED or corridor of the thrombosis clinic. ${ }^{16}$ They were permitted to use any walking aids, if applicable; otherwise, patients walked without any assistance and were on room air. Patients were accompanied by a research assistant who was responsible for recording oxygen saturation, heart rate, and respiration rate on a case record form at baseline. Continuous recordings were taken during the walk test with electronic printouts from the equipment used. Peak changes during the walk test as well as at 1-minute post-walk test were recorded. The participant's respiration rate was assessed only pre- and post-walk test because it was difficult to have an accurate peak respiratory rate during ambulation with the study monitor that was used. We allowed the participants to recover for a period of 1 minute before checking the post-walk test vital signs. The research assistant carried all necessary equipment, including the pulse oximeter (model 504-DXP; Criticare Systems Inc., Waukesha, WI, USA), leaving the patients free to ambulate independently at their own pace.

The walk test was discontinued if patients experienced worsening dyspnea, had an oxygen saturation less than $86 \%$ for 30 seconds, had a heart rate higher than 110 for heart failure patients or 120 for chronic obstructive pulmonary disease patients for greater than 60 seconds, complained of new or worsening chest pain, or if they requested the discontinuation for any reason, as previously published. ${ }^{16}$ Discontinued walk tests were considered a positive test if any of the stopping rules were implemented, but not in the case of patient requests. Standardized data collection forms were used. The study authors collected outcome data and demographics using an additional study form. Data were entered into a computerized database using SPSS version 20.1 software (IBM Corporation, Chicago, IL, USA).

\section{Outcome measures}

The primary outcome of interest was pulmonary embolism. This was defined as any pulmonary embolism treated by thrombosis physicians following confirmatory diagnostic testing. Diagnostic confirmation was made using computed tomography pulmonary angiogram and included any segmental, subsegmental, or saddle embolism. Ventilation perfusion scans followed the currently accepted standard criteria, ${ }^{18}$ and intermediate or high probability results were deemed to be a positive outcome. Compression ultrasound to diagnose deep vein thrombosis (DVT) utilized The Ottawa Hospital's protocol, which looks for noncompressibility at the trifurcation of the popliteal vein or above or any new non-compressibility at the trifurcation of the popliteal vein or above if prior imaging was made available. A positive DVT study in a patient suspected of pulmonary embolism was also deemed to be a positive outcome.

The primary outcome, pulmonary embolism, was assessed in all enrolled patients by the study authors, 
based on predefined diagnostic imaging criteria. Final radiology reports were used to confirm the presence of a pulmonary embolism. Indeterminate results were classified as no pulmonary embolism unless the thrombosis physician treated the patient as having a pulmonary embolism.

\section{Sample size calculation}

Diagnostic tests should have a high sensitivity to ensure that patients with pulmonary embolism receive treatment, along with specificity as high as possible to maintain the utility of the test. ${ }^{19} \mathrm{We}$ decided a priori that we sought to determine whether the sensitivity of an ambulatory oxygen saturation and ambulatory heart rate test exceeded $70 \%$. However, conservatively assuming that $30 \%$ of suspected pulmonary embolisms are confirmed and that the sensitivity of the walk test results exceeds $80 \%$, we sought to show that the lower bound of the confidence interval $(\mathrm{CI})$ would be $>70 \% \pm 10 \%$. Based on this, we determined that a sample size of 270 was necessary to obtain the lower level CI.

\section{Data analysis}

Data were placed into standard two-by-two tables to calculate exact binomial 95\% CIs for sensitivity, specificity, and likelihood ratios of the walk test for identifying patients with pulmonary embolism. Descriptive and univariate analyses with students' two-sided $t$-test and $\chi$-square tests were conducted to determine cut-points with a sensitivity of $\geq 70 \%$, following the optimal cut-point that was then determined. Potential cut-points were determined based on clinically meaningful and easily remembered whole numbers.

\section{RESULTS}

\section{Characteristics of study subjects}

Of the 123 patients assessed for eligibility, 114 were recruited (Figure 1). Of these, $30(26.3 \%)$ were ultimately diagnosed with pulmonary embolism. There were $75(65.8 \%)$ participants who had a positive walk test. Only one participant $(0.9 \%)$ was treated for a pulmonary embolism, despite having indeterminate imaging results. This individual was known to have a recurrent thromboembolic disease with lupus anticoagulant along with a positive walk test. Figure 1 provides

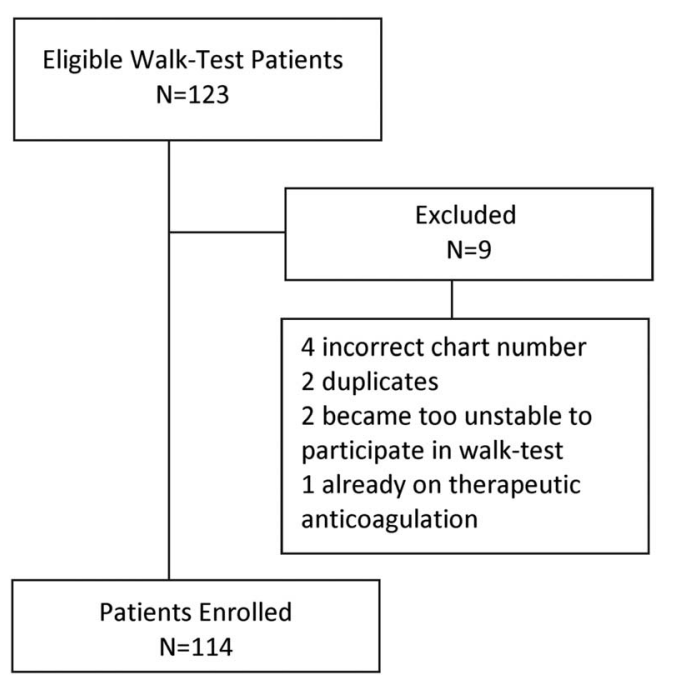

Figure 1. Study Enrollment.

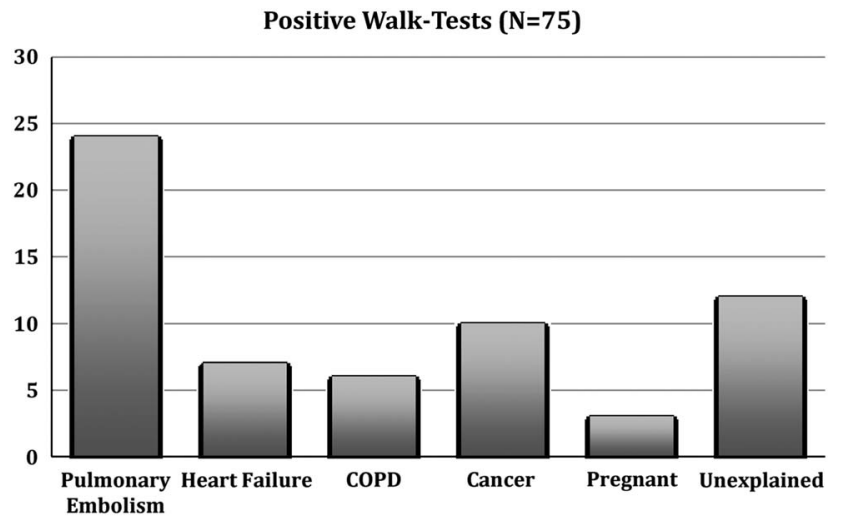

Figure 2. Breakdown of Positive Walk-tests.

details for the nine patients who were assessed for eligibility but were not enrolled.

Baseline characteristics of the study groups, stratified by outcome, are presented in Table 1 . Of the alternative diagnoses for a positive walk test, heart failure and chronic obstructive pulmonary were most common.

We calculated mean values of the ambulatory walk tests, and these are stratified by outcomes and presented in Table 2. The mean value of an ambulatory heart rate among all participants was 100.6 beats per minute (BPM), and the mean ambulatory oxygen saturation level among all participants was $93.6 \%$.

\section{Main results}

An ambulatory oxygen saturation absolute drop of $\geq 2 \%$ and an ambulatory heart rate change of $>10$ BPM were 


\begin{tabular}{|c|c|c|c|}
\hline Characteristic & Total no. $(\%, N=114)$ & $\operatorname{PE}(\%, N=30)$ & Non-PE $(\%, N=84)$ \\
\hline Age, years, mean & 52.9 & 54.6 & 52.4 \\
\hline Female sex (\%) & $72(63.2)$ & $13(18.1)$ & 59 (81.9) \\
\hline \multicolumn{4}{|l|}{ Hospital* } \\
\hline General hospital & $30(26.3)$ & $6(5.3)$ & $24(21.1)$ \\
\hline Civic hospital & $39(34.2)$ & $9(7.9)$ & $30(26.3)$ \\
\hline Thrombosis clinic & $45(39.5)$ & $15(13.2)$ & $30(26.3)$ \\
\hline \multicolumn{4}{|l|}{ Past medical history } \\
\hline $\mathrm{COPD}^{\dagger}$ & $8(7.0)$ & $1(12.5)$ & 7 (87.5) \\
\hline Heart failure & $15(13.2)$ & $1(6.6)$ & $14(93.3)$ \\
\hline Previous DVT/PE ${ }^{\ddagger}$ & $8(7.0)$ & $4(50.0)$ & $4(50.0)$ \\
\hline Cancer & $16(14.0)$ & $9(56.3)$ & $7(43.8)$ \\
\hline Pregnancy & $4(3.5)$ & $0(0.0)$ & $4(3.5)$ \\
\hline \multicolumn{4}{|l|}{ Symptoms on arrival } \\
\hline Chest pain & $70(61.4)$ & $18(25.7)$ & $52(74.3)$ \\
\hline Shortness of breath & $78(68.4)$ & $25(32.1)$ & $53(67.9)$ \\
\hline Syncope & $6(5.3)$ & 2 (33.3) & $4(66.7)$ \\
\hline Extremity swelling & $15(13.2)$ & $2(13.3)$ & $13(86.7)$ \\
\hline \multicolumn{4}{|l|}{ Symptom onset } \\
\hline$<24 \mathrm{hrs}$ & $35(30.7)$ & $11(31.4)$ & $24(68.6)$ \\
\hline $1-7$ days & $59(51.8)$ & $19(32.2)$ & $40(67.8)$ \\
\hline$>7$ days & $20(17.5)$ & $9(45.0)$ & $11(55.0)$ \\
\hline \multicolumn{4}{|l|}{ Diagnostics } \\
\hline CT pulmonary angiography & $51(44.7)$ & $18(35.3)$ & $29(56.9)$ \\
\hline Indeterminate & $4(7.8)$ & $0(0.0)$ & $4(7.8)$ \\
\hline Ventilation perfusion scan & $34(29.8)$ & 12(35.3) & $22(64.7)$ \\
\hline High probability & 7 (20.6) & $7(20.6)$ & $0(0.0)$ \\
\hline Intermediate probability & $6(17.6)$ & $5(1.7)$ & $1(2.9)$ \\
\hline Ultrasound $^{\S}$ & $11(9.6)$ & & \\
\hline Completed 3-minute walk test & $101(88.6)$ & $26(25.7)$ & $75(74.3)$ \\
\hline \multicolumn{4}{|c|}{ Reason 3-minute walk test not completed } \\
\hline Dyspnea & $4(3.5)$ & $1(25.0)$ & $3(75.0)$ \\
\hline Fatigue & $6(5.3)$ & $1(16.7)$ & $5(83.3)$ \\
\hline Patient request & $2(1.8)$ & $0(0.0)$ & $2(100.0)$ \\
\hline Stopping rules" & $5(4.4)$ & $3(60.0)$ & $2(40.0)$ \\
\hline 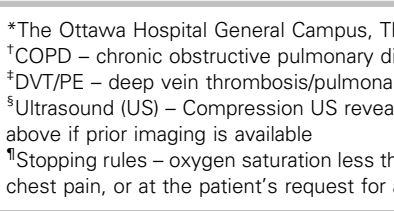 & $\begin{array}{l}\text { Civic Campus, The Ottawa Hospi } \\
\text { us patient history } \\
\text { ibility at the trifurcation of the po } \\
\text { nds, a heart rate higher than } 110\end{array}$ & $\begin{array}{l}\text { c all signify different cli } \\
\text { or ii) new non-compre } \\
\text { ents or } 120 \text { for COPD p }\end{array}$ & $\begin{array}{l}\text { ment. } \\
\text { ation of the popliteal vein or } \\
\text { n } 60 \text { seconds, complaints of }\end{array}$ \\
\hline
\end{tabular}

the optimal cut-points. The majority of the positive walk tests in the study populations were attributed to pulmonary embolism, but there were also positive walk tests in patients who did not have a pulmonary embolism (Figure 2). Of these two assessments, the ambulatory heart rate increase of $>10 \mathrm{BPM}$ was superior, with a sensitivity of $96.6 \%$ (95\% CI 83.3 to 99.4) and specificity of $31.0 \%$ (95\% CI 22.1 to 45.0 ) for pulmonary embolism (Table 3). An ambulatory oxygen saturation absolute drop of $\geq 2 \%$ had a sensitivity of $80.2 \%$ (95\% CI 62.7 to 90.5 ) and a specificity of $39.3 \% \quad(95 \%$ CI 29.5 to 50.0$)$ for pulmonary embolism.

Combining an ambulatory heart rate change of $>10$ BPM with an absolute change in ambulatory oxygen saturation $\geq 2 \%$ yielded a sensitivity of $100.0 \%$ (95\% CI 88.7 to 100.0 ) with a specificity of $11.9 \%$ (95\% CI 6.6 to 21.0) for pulmonary embolism. 


\begin{tabular}{|c|c|c|c|}
\hline Variable & Positive pulmonary embolism \pm STD & Negative pulmonary embolism \pm STD & $P$ value \\
\hline \multicolumn{4}{|c|}{$\begin{array}{l}\text { Mean heart rate, beats } \\
\text { per minute }( \pm \text { STD })\end{array}$} \\
\hline Baseline & $82.8 \pm 13.9$ & $79.1 \pm 14.9$ & 0.24 \\
\hline Ambulatory & $108.3 \pm 12.6$ & $97.8 \pm 13.5$ & $<0.01$ \\
\hline Recovery & $88.2 \pm 15.5$ & $81.4 \pm 15.4$ & 0.04 \\
\hline \multicolumn{4}{|c|}{$\begin{array}{l}\text { Mean oxygen saturation, } \\
\%( \pm \text { STD })\end{array}$} \\
\hline Baseline & $96.9 \pm 1.7$ & $97.7 \pm 1.5$ & $<0.01$ \\
\hline Ambulatory & $91.3 \pm 4.6$ & $94.5 \pm 3.5$ & $<0.01$ \\
\hline Recovery & $95.9 \pm 3.3$ & $97.2 \pm 2.3$ & 0.02 \\
\hline \multicolumn{4}{|c|}{$\begin{array}{l}\text { Mean respiration rate, } \\
\text { per min }( \pm \text { STD })\end{array}$} \\
\hline Baseline & $18.1 \pm 5.1$ & $17.7 \pm 2.6$ & 0.02 \\
\hline Ambulatory & $\mathrm{n} / \mathrm{a}$ & $\mathrm{n} / \mathrm{a}$ & $\mathrm{n} / \mathrm{a}$ \\
\hline Recovery & $19.6 \pm 3.9$ & $19.2 \pm 2.9$ & $<0.01$ \\
\hline
\end{tabular}

\begin{tabular}{|c|c|c|c|c|}
\hline \multirow[b]{2}{*}{ Test characteristic } & \multirow{2}{*}{$\begin{array}{c}\text { Sensitivity } \\
95 \% \mathrm{Cl}\end{array}$} & \multirow{2}{*}{$\begin{array}{c}\text { Specificity } \\
95 \% \mathrm{Cl}\end{array}$} & \multicolumn{2}{|c|}{ Likelihood ratio $(95 \% \mathrm{Cl})$} \\
\hline & & & Positive & Negative \\
\hline Ambulatory heart rate change $>10$ BPM & $0.97(0.83-0.99)$ & $0.31(0.22-0.42)$ & $1.40(1.20-1.64)$ & $0.11(0.02-0.76)$ \\
\hline Absolute ambulatory oxygen saturation drop $\geq 2 \%$ & $0.80(0.63-0.91)$ & $0.39(0.30-0.50)$ & $1.32(1.03-1.69)$ & $0.51(0.24-1.09)$ \\
\hline Ambulatory heart rate + ambulatory oxygen saturation & $1.00(0.88-1.00)$ & $0.11(0.06-0.20)$ & $1.14(1.05-1.23)$ & Infinity \\
\hline
\end{tabular}

\section{LIMITATIONS}

This study was conducted at two ED sites, and we had relatively few patients with pulmonary embolism in our study, which potentially limits the generalizability of the results. The inclusion criteria used physician gestalt for many patients in whom pulmonary embolism was not yet confirmed. An ideal assessment would require the application of the 3-minute walk test to all comers in the ED with clearly defined inclusion criteria. Our recruitment model could have led to an observation bias. The research assistants conducting the walk test may have looked more cautiously at the patients during the walk test. This has the potential to lead to more patients with a known diagnosis (of pulmonary embolism) as having a positive walk test. However, we used predefined criteria for what a positive walk test would constitute and included a strategy that involved continuous monitoring during the walk test. This allowed us to review the study monitor electronic printouts afterward to reconfirm the peak vital signs, so we believe that the potential bias we describe had minimal impact on the study and our assessments. Additionally, the incidence of pulmonary embolism in our subset was $26.3 \%$, which was very similar to the reported incidence of $30.0 \% .^{6-8}$

Several patients had other pre-existing diagnoses, in particular, heart failure and chronic obstructive pulmonary disease. Both illnesses are known to have the potential to result in a positive walk test. ${ }^{16}$ This may have led to an over-representation in the number of positive walk tests due to etiologies other than pulmonary embolism. Fortunately, our study population had a relatively low proportion with coexisting medical illnesses. A total of $13(11.4 \%)$ participants had a diagnosis of heart failure and/or chronic obstructive pulmonary disease. Thus, we believe that any impact that this has had on our results was unlikely to be substantial. Moreover, both heart failure and chronic obstructive pulmonary disease have historical, physical, and diagnostic testing unique to them and are less likely to obscure the physician's ability to include or exclude them as a diagnosis when encountered, likely accounting for a very low number of these patients in our study. 
During our sample size calculation, we determined that 270 patients were required. However, our study was stopped after 123 patients were enrolled because of financial restrictions. Despite this low sample size, we were still able to derive sensitive and clinically meaningful results.

Finally, the use of noninvasive diagnostic tests as part of the reference standard could be considered a limitation in this study. Although pulmonary angiography remains the gold standard for the diagnosis of pulmonary embolus, no participant in our study underwent one. The use of noninvasive diagnostic tests for the diagnosis or exclusion of pulmonary embolism has become the clinical standard since the PIOPED II trial. ${ }^{20}$

\section{DISCUSSION}

In this prospective diagnostic cohort study, we found that change in ambulatory heart rate and change in ambulatory oxygen saturation are both sensitive measurements in the workup of pulmonary embolism. Of the two assessments, an ambulatory heart rate difference $>10$ BPM from baseline was the superior measurement. However, combining a drop in ambulatory oxygen saturation with a heart rate change $>10 \mathrm{BPM}$ yielded the highest sensitivity.

A number of clinical decision rules have been derived to assess the pretest probability in patients suspected to have pulmonary embolism. ${ }^{11,15,18,21-35}$ The three most widely used clinical decision rules are the simplified Wells score, the revised Geneva score, and the pulmonary embolism rule-out criteria (PERC) rule. The simplified Wells score comprises seven variables and has been derived and validated in the North American population. ${ }^{28,38}$ The revised Geneva score, which consists of a series of similar measures to the simplified Wells score, contains nine variables encompassing risk factors, symptoms, and clinical signs and has also been found to have a high degree of reliability. ${ }^{28}$ The PERC rule, which was designed to exclude pulmonary embolism without further testing, consists of eight variables, all of which need to be met in order to conclude that a $<2 \%$ venous thromboembolic rate exists. The simplified Wells score includes a subjective criterion, which may be loosely interpreted: "pulmonary embolism is the most likely diagnosis." This has resulted in criticism that there can be variation from clinician to clinician in score calculation. ${ }^{26-29}$ Consequently, these rules are often underutilized by practicing clinicians. ${ }^{29-30}$ This may lead to inappropriate management with resultant increased morbidity and mortality. ${ }^{32}$

All existing decision-making rules include stationary vital sign measurements. ${ }^{13,18,34-35}$ To the best of our knowledge, ours is the first study to consider the diagnostic power of ambulatory vital signs in an ED setting. The use of an oxygen saturation level in pulmonary embolism has been looked at in a recent study, showing that a pulse oximetry cut-off of $95 \%$ room air oxygen saturation at sea level can effectively differentiate patients with pulmonary embolism into highand low-risk groups. ${ }^{33}$ Another study evaluated the benefit of a treadmill exercise oxygen saturation test, by way of respiratory gas exchange analysis to help diagnose pulmonary embolism in locations where immediate imaging is not available. ${ }^{37}$ The authors concluded that exercise-induced desaturation might be sensitive and specific for diagnosing pulmonary embolism. Although the results of this study were compelling, its results are not feasible for application in a clinical setting because advanced equipment and laboratory analysis were used. Although previously published papers support the physiology of ambulatory oxygen saturation and heart rate, ${ }^{37,38}$ none have considered this in the workup of pulmonary embolism in an ED setting. Our study has identified two new objective measurements that may help improve the sensitivity of pre-existing decision rules.

Future research must look at the implications of using ambulatory vital signs (heart rate difference and oxygen saturation drop) together with pre-existing rules to determine whether overall diagnosis and subsequent morbidity and mortality are affected.

In summary, our study found that an ambulatory heart rate change $>10 \mathrm{BPM}$ or a $\geq 2 \%$ absolute decrease in ambulatory oxygen saturation from baseline during a standardized 3-minute walk test is highly correlated with pulmonary embolism. Although the findings appear promising, neither of these variables can currently be recommended as a screening tool for pulmonary embolism until larger prospective studies examine their performance either alone or with preexisting rules. ${ }^{39,40}$

\section{Competing interests: None declared.}

Grant funding: Provided by the Department of Emergency Medicine and Department of Medicine, The Ottawa Hospital, University of Ottawa, ON. 
Acknowledgements: QA and JP conceived the study, designed the trial, and obtained research funding. JP, MR, and IS supervised the conduct of the trial and data collection. QA and SM undertook recruitment of participating centres and patients and managed the data, including quality control. JP, MR, and IS provided statistical advice on study design. JP and QA analysed the data. QA drafted the manuscript, and all authors contributed substantially to its revision. QA takes responsibility for the paper as a whole.

Presentation: Presented at the Canadian Association of Emergency Physicians (CAEP) 2013 Annual Scientific Meeting, Vancouver, BC, Canada.

\section{REFERENCES}

1. Brown BE, Braithwait SA, Perina D. Rosen's emergency medicine - concepts and clinical practice. In J. Marx, R. Hockberger, \& R. Walls (Eds.), Dyspnea/chest pain (pp. 206-214). Philadelphia: Saunders; 2013.

2. Dismuke SE, Wagner EH. Pulmonary embolism as a cause of death. The changing mortality in hospitalized patients. FAMA 1986;255:2039-42.

3. Anderson FA Jr, Wheeler HB, Goldberg RJ, et al. A population-based perspective of the hospital incidence and case-fatality rates of deep vein thrombosis and pulmonary embolism. The Worcester study. Arch Intern Med 1991; 151:933-8.

4. Silverstein MD, Heit JA, Mohr DN, et al. Trends in the incidence of deep vein thrombosis and pulmonary embolism: a 25-year population-based study. Arch Intern Med 1998;158:585-93.

5. Nordstrom M, Lindblad B. Autopsy-verified venous thromboembolism within a defined urban population-the city of Malmo, Sweden. APMIS 1998;106:378-84.

6. White RH. The epidemiology of venous thromboembolism [review]. Circulation 2003;107:4-7.

7. Dalen JE, Alpert JS. Natural history of pulmonary embolism. Prog Cardiovasc Dis 1975;17:259-70.

8. Carson JL, Kelley MA, Duff A, et al. The clinical course of pulmonary embolism. $N$ Engl 7 Med 1992;326:1240-5.

9. Alpert JS, Smith R, Carlson CJ, et al. Mortality in patients treated for pulmonary embolism. FAMA 1976;236:1477-80.

10. Kruip MJHA Leclercq MGL, van der Heul C, et al. Diagnostic strategies for excluding pulmonary embolism in clinical outcome studies: a systematic review. Ann Intern Med 2003;138:941-51.

11. PIOPED Investigators. Value of the ventilation/perfusion scan in acute pulmonary embolism. Results of the prospective investigation of pulmonary embolism diagnosis (PIOPED). 7AMA 1990;263:2753-9.

12. Wells PS, Ginsberg JS, Anderson DR, et al. Use of a clinical model for safe management of patients with suspected pulmonary embolism. Ann Intern Med 1998;129: 997-1005.

13. Hull RD, Hirsh J, Carter CJ, et al. Pulmonary angiography, ventilation lung scanning, and venography for clinically suspected pulmonary embolism with abnormal perfusion lung scan. Ann Intern Med 1983;98:891-9.
14. Wicki J, Perneger TV, Junod AF, et al. Assessing clinical probability of pulmonary embolism in the emergency ward: a simple score. Arch Intern Med 2001;161:92-7.

15. Le Gal G, Righini M, Roy PM, et al. Prediction of pulmonary embolism in the emergency department: the revised Geneva score. Ann Intern Med 2006;144:165-71.

16. Pan AM, Stiell I. Feasibility of a structured 3-minute walk test as a clinical decision tool for patients presenting to the emergency department with acute dyspnoea. Emerg Med 7 2009;26(4):278-82.

17. Stiell IG, Clement CM, Brison RJ, et al. A risk scoring system to identify emergency department patients with heart failure at high risk for serious adverse events. Acad Emerg Med 2013;20(1):17-26.

18. Perrier A, Desmarais S, Miron MJ, et al. Non-invasive diagnosis of venous thromboembolism in outpatients. Lancet 1999;353:190-5.

19. Miniati M, Monti S, Bottai M. A structured clinical model for predicting the probability of pulmonary embolism. Am $\mathcal{f}$ Med 2003;114:173-9.

20. Stein PD, Fowler SE, Goodman LR, et al. Multidetector computed tomography for acute pulmonary embolism. $N$ Engl 7 Med 2006;354(22):2317-27.

21. Rodger MA, Jones G, Rasuli P, et al. Steady-state end-tidal alveolar dead space fraction and D-dimer: bedside tests to exclude pulmonary embolism. Chest 2001;120:115-9.

22. Rodger MA, Raymond F, Stiell I, et al. Development and validation of a simple clinical prediction rule to exclude pulmonary embolism. Blood 1999;94(10):27.

23. Rodger MA, Bredeson CN, Jones G, et al. The bedside investigation of pulmonary embolism diagnosis study: a double-blind randomized controlled trial comparing combinations of 3 bedside tests vs ventilation-perfusion scan for the initial investigation of suspected pulmonary embolism. Arch Intern Med 2006;166:181-7.

24. Kline JA, Wells PS. Methodology for a rapid protocol to rule out pulmonary embolism in the emergency department. Ann Emerg Med 2003;42:266-76.

25. Kline JA, Meek S, Boudrow D, et al. Use of the alveolar dead space fraction $(\mathrm{Vd} / \mathrm{Vt})$ and plasma D-dimers to exclude acute pulmonary embolism in ambulatory patients. Acad Emerg Med 1997;4:856-63.

26. Wells PS, Anderson DR, Rodger MA, et al. Derivation of a simple clinical model to categorize patients probability of pulmonary embolism: increasing the models utility with the SimpliRED D-dimer. Thromb Haemost 2000;83: 416-420.

27. Carrier M, Wells PS, Rodger MA. Excluding pulmonary embolism at the bedside with low pre-test probability and D-dimer: safety and clinical utility of 4 methods to assign pre-test probability. Thromb Res 2006;117:469-474.

28. Wells PS, Anderson DR, Rodger M, et al. Excluding pulmonary embolism at the bedside without diagnostic imaging: management of patients with suspected pulmonary embolism presenting to the emergency department by using a simple clinical model and D-dimer. Ann Intern Med 2001;135(2):98-107.

29. Stein PD, Henry JW. Prevalence of acute pulmonary embolism among patients in a general hospital and at autopsy. Chest 1995;108:978-81. 
30. Clark JS, Votteri B, Ariagno RL, et al. Noninvasive assessment of blood gases. Am Rev Respir Dis 1992;145: 220-232.

31. Van Belle A, Buller HR, Huisman MV, et al. Effectiveness of managing suspected pulmonary embolism using an algorithm combining clinical probability, D-dimer testing, and computed tomography. $7 A M A$ 2006;295: 172-179.

32. Roy PM, Meyer G, Vielle B, et al. Appropriateness of diagnostic management and outcomes of suspected pulmonary embolism. Ann Intern Med 2006;144:157-164.

33. Perrier A, Roy PM, Sanchez O, et al. Multidetector-row computed tomography in suspected pulmonary embolism. $N$ Engl 7 Med 2005;352:1760-8.

34. Stein PD, Goldhaber SZ, Henry JW. Alveolar-arterial oxygen gradient in the assessment of acute pulmonary embolism. Chest 1995;107:139-43.
35. Rodger MA, Makropoulos D, Turek M, et al. Diagnostic value of the electrocardiogram in suspected pulmonary embolism. Am 7 Cardiol 2000;86:807-9.

36. Davies CW, Wimperis J, Green ES, et al. Early discharge of patients with pulmonary embolism: a two-phase observational study. Eur Respir 7 2007;30:708-14.

37. Topilsky Y, Courtney L, Hayes MS, et al. Cardiopulmonary exercise test in patients with subacute pulmonary emboli. Heart Lung 2012;41(2):125-36.

38. Arena R, Sietsema K. Cardiopulmonary exercise testing in the clinical evaluation of patients with heart and lung. Circulation 2011;123:668-80.

39. Calisir C, Yavas US, Ozkan IR, et al. Performance of the Wells and revised Geneva scores for predicting pulmonary embolism. Emerg Med 2009;16(1):49-52.

40. Freitas JE, Sarosi MG. Modified PIOPED criteria used in clinical practice. 7 Nucl Med 1995;36(9):1573-8. 